\title{
Os Verbos de Dizer em Resenhas Acadêmicas ${ }^{1}$
}

Siderlene MUNIZ-OLIVEIRA

LAEL / PUC-SP

Resumo: Temos como objetivo, neste artigo, apresentar os resultados de uma pesquisa de mestrado, onde fizemos um levantamento de verbos introdutores de discurso relatado em resenhas acadêmicas e propomos uma classificação para os verbos, apontando algumas sugestões para o processo de ensino-aprendizagem de resenhas no que se refere à utilização dos verbos de dizer. Utilizamos para a classificação dos verbos conceitos do interacionismo sócio-discursivo, como as operações de linguagem.

Palavras-Chave: Resenhas, discurso relatado, textos acadêmicos, capacidades de linguagem.

Abstract: We aims in this paper to present the findings of a master's degree research, which collecting and proposing a classification for reported speech introductory verbs, pointing some suggestions for critical review teaching and learning as far as reported speech verbs are concerned. We use for this classification some theoreticalmethodological framework of socio-discursive interactionism, such linguistic operations.

Key Words: Critical review, reported speech, academic texts, language capacities.

Resumen: Tenemos como objetivo, en este artículo, presentar los resultados de una investigación de máster, donde hicimos un levantamiento de verbos introdutores de discurso relatado en reseñas académicas y proponemos una clasificación para los verbos, apuntando algunas sugerencias para el proceso de enseñanza de reseñas en el que se refiere a la utilización de los verbos de decir. Utilizamos para la

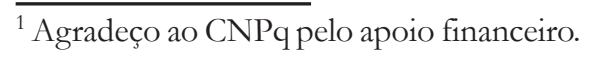


clasificación de los verbos conceptos del interacionismo sociodiscursivo, como las operaciones de lenguaje.

Palavras claves: Reseñas, discurso relatado, capacidad de lenguaje, texto académico.

\section{Introdução}

Diversos pesquisadores vêm revelando a dificuldade dos alunos de graduação na produção de textos acadêmicos (MACHADO, 2004; SILVA; MATA, 2002; MATÊNCIO, 2002; MOTTA-ROTH, 2003). Dentre esses pesquisadores, podemos citar Silva e Mata (2002) e Matêncio (2002) que trabalham com o gênero resumo e Machado (2004) que trabalha com o gênero resenha, visando construir propostas para as dificuldades que os alunos de graduação revelam ao produzir esses textos e relatar o discurso do outro. Muniz-Oliveira (2004) afirma que a dificuldade em inserir as vozes no texto ao relatar o discurso do outro não é só dos alunos de graduação, mas também dos alunos de pós-graduação, pois esses alunos também apresentam esta dificuldade para redigir textos pertencentes a diferentes gêneros acadêmicos como resumos, resenhas, projetos de pesquisa, artigos, dissertações e teses.

Diante dessa problemática, os alunos apresentam dificuldades não só para separar as vozes como também para empregar os verbos adequados ao relatar o discurso do outro. Assim, este artigo tem o objetivo de apresentar os resultados de uma pesquisa de mestrado $^{2}$ na qual foi feito um levantamento dos verbos usados para inserir o discurso do outro em resenhas acadêmicas, atentando para as diferenças de significados dos verbos e propondo uma classificação para os mesmos.

Em nosso estudo, consideramos a resenha um metatexto, ${ }^{3}$ ou seja, um texto que mantém uma relação de comentário sobre outro texto. A resenba tem como função contextualizar a disciplina na qual a

\footnotetext{
${ }^{2}$ Pesquisa realizada por Muniz-Oliveira (2004), integrante do grupo ALTER (Análise de Linguagem, Trabalhado Educacional e suas Relações) da PUC-SP, coordenado pela minha orientadora Profa. Dra. Anna Rachel Machado, a quem agradeço as orientações valiosas para a realização da pesquisa.

${ }^{3}$ Ver classificação de Genette (1981).
} 
obra se insere, situar o autor da obra resenhada na disciplina em questão, descrever a obra, ressaltando a estrutura da mesma, tornando conhecido um livro recentemente publicado. A resenha crítica, além dessas características da resenha, apresenta como característica fundamental a avaliação da obra resenhada, sendo o objetivo do resenhador o de convencer o destinatário sobre a validade da obra a partir do julgamento de valor. Nas resenhas críticas, além dos itens lexicais avaliativos que podem aparecer também nas resenhas, já que não há neutralidade na linguagem, há uma parte, geralmente nos últimos parágrafos, dedicada exatamente à avaliação do livro, no qual se destacam pontos específicos da obra resenhada, podendo, ainda, o resenhador recomendar ou não o livro ou recomendá-lo apesar das falhas indicadas (ARAÚJO, 1996; BEZERRA, 2001; MACHADO, no prelo a; MOTTA-ROTH, 1995).

\section{O Discurso Direto e o Discurso Indireto}

Seguindo a concepção dialógica de linguagem, encontramos em uma enunciação as vozes dos diferentes papéis desempenhados pelos participantes em um discurso. Assim, o discurso é constituído de modo polifônico, em um jogo de várias vozes que se cruzam, em complementação ou em contradição (BAKHTIN, 2000).

Considerando que o discurso é constituído de modo polifônico, a presença do outro pode estar marcada lingüisticamente por meio de formas gramaticais, ou pode ser identificável a partir do próprio enunciado. Vários são os autores que se dedicaram a identificar e a categorizar as marcas da polifonia no discurso em geral (MAINGUENEAU, 1997, 2001; AUTHIER-REVUZ, 1982, 2001). Uma das autoras mais importantes é Authier-Revuz (1982), que desenvolveu os conceitos de heterogeneidade constitutiva e heterogeneidade mostrada como características do discurso.

Para a autora, a heterogeneidade constitutiva não produz marcas que evidenciam presença do outro na produção do discurso, porém deixa entrever os diversos discursos que lhe deram origem e que representam os diferentes grupos sociais em que circulam. A heterogeneidade constitutiva seria, para a autora, o princípio que fundamenta a própria natureza da linguagem. Por sua vez, a heterogeneidade mostrada, oriunda de diversas fontes enunciativas, se 
torna evidente por meio das formas de discurso relatado, de conotação autonímica, de ironia, de imitação etc.

Auhier-Revuz (2001), ao estudar as formas do discurso relatado, como o discurso direto e o discurso indireto, postula que o que um DR (discurso relatado) relata não é uma frase ou um enunciado, mas um ato de enunciação, definido por um par de interlocutores que está situado numa situação X num determinado tempo e lugar. Assim, para a autora, o DR é um ato de enunciação caracterizado como um acontecimento particular e é objeto de outro ato de enunciação, que é uma mensagem caracterizada como constituindo um DR.

Para Authier-Revuz (2001), o que caracteriza todo DR (como o discurso direto e discurso indireto) é que a situação de enunciação, na qual e pela qual a mensagem relatada ganha sentido, não é uma situação de fato, como em um ato de fala ordinário, mas está presente apenas pela descrição que o interlocutor faz dela na mensagem caracterizada como constituindo um DR. Disso decorre a extrema importância dos sintagmas introdutores do DR, nos quais estão em jogo a variedade lexical dos verbos dicendi, cujo sentido indica que há uma enunciação encaixada em outra. Assim, o verbo introdutor fornece um certo quadro no interior do qual será interpretado o discurso citado.

Para a autora, no que se refere à estrutura sintática do discurso indireto, não é só a clássica subordinação em que verbo dicendi + que "João disse que" faz com que reconheçamos um discurso indireto, pois há diversas outras estruturas sintáticas para o mesmo. Podemos citar como exemplo a subordinação no infinitivo como "João pediu para vir", a oração que tem como complemento um nome "João ordenou a partida" e, até mesmo, há outros determinados verbos, que, sozinhos, mostram outra enunciação como "João felicitou-a".

Em nossa pesquisa, iremos analisar os verbos introdutores de discurso relatado (discurso direto e discurso indireto, daqui em diante DD e DI) em resenhas acadêmicas. O nosso estudo vai enfatizar, a partir dos verbos, as operações que o resenhador atribui ao autor do texto resenhado, visando compreender quais operações são interpretadas pelo resenhador, o que consideramos fundamental para o ensino-aprendizagem de resenhas e, conseqüentemente, poderá auxiliar o trabalho do professor. 
Assim, vamos utilizar, de forma mais geral, os pressupostos do interacionismo sócio-discursivo (ISD), que considera o texto como a materialização de uma ação de linguagem constituída por uma série de operações.

Considerando a resenha crítica a materialização de uma ação de linguagem, vamos tentar compreender como o resenhador interpreta as operações de linguagem do autor do texto resenhado e de que forma essas operações são interpretadas pela comunidade acadêmica de modo mais ou menos normatizada. Assim, na próxima seção, vamos apresentar alguns conceitos do ISD como operação de linguagem e capacidades de linguagem, conceitos esses que nortearão o nosso trabalho.

\section{As Operações de Linguagem, as Capacidades de Linguagem e o Modelo de Análise}

\subsection{As operações de linguagem}

Para o ISD, as operações de linguagem compreendem os processos particulares para a realização das ações de linguagem que são necessárias para a concretização das tarefas. Desse modo, a forma de se atingir os objetivos da ação constitui-se como tarefas a serem realizadas por meio de determinadas operações (MACHADO, no prelo b).

Essas operações, segundo Bronckart (2003, p. 109), "não descrevem os mecanismos mentais e comportamentais que um agente põe em funcionamento on line, isto é, na temporalidade e no curso efetivo da produção de um texto"; mas considerando as possibilidades, buscam conceitualizar e hierarquizar as escolhas ou decisões que as características de um texto revelam objetivamente. Essas operações não podem ser consideradas puramente cognitivas, mas já pré-existem historicamente no ambiente sócio-semiótico e quando o agente se apropria delas, consistem sempre nessa interação dialética entre dimensões histórico-sociais dos gêneros, dimensões semânticas das línguas naturais e dimensões sincrônicas das representações sobre as situações de ação. Essas operações, no decorrer da história foram se constituindo, e o ser humano, no seu desenvolvimento, apropria-se 
dela. Desse modo, é importante enfatizar que seu caráter não é meramente cognitivo, mas "sócio-histórico de construção". ${ }^{4}$

A ação de linguagem pode ser vista como um conjunto de operações que envolvem a linguagem, constituindo uma unidade, podendo ser atribuída a responsabilidade de sua realização a um indivíduo particular, que seria movido por motivos e orientado por objetivos, no quadro de uma atividade social. Quando o agente tem domínio, maestria nessas operações, pode-se dizer que ele desenvolveu capacidades necessárias para a ação. Essas ações, operações e capacidades não são inatas, mas aprendidas no decorrer da história dos agentes, no quadro das diferentes atividades e avaliações sociais de que participam (MACHADO, 2004).

\subsection{Capacidades de linguagem}

A partir das definições de operação e ação, os pesquisadores de Genebra construíram um quadro teórico para conceitualizar a ação de linguagem, pretendendo caracterizar o conjunto de operações que estão nela envolvidas. Do mesmo modo, o conceito de capacidades de linguagem (DOLZ; PASQUIER; BRONCKART, 1993) visa caracterizar a maestria dos agentes nessas operações (MACHADO, no prelo b). Assim, compreendemos por que tanto as operações quanto as capacidades estão classificadas em três tipos: de ação, discursivas e lingüístico-discursivas.

As capacidades de ação envolveriam operações de mobilização de representações sobre o contexto-físico e sócio-subjetivo, no qual se desenvolve a ação de linguagem, sobre os conteúdos a serem verbalizados e a operação de "escolha" de um determinado gênero de texto.

As capacidades discursivas implicam as operações de gerenciamento da infra-estruturação geral do texto, que é constituída pelo plano global do texto, pelos tipos de discurso e pelas seqüências ${ }^{5}$ que eventualmente possam aparecer e pelas outras formas de planificação global e local do conteúdo do texto.

\footnotetext{
${ }^{4}$ Machado (2004) em comunicação oral.

${ }^{5}$ Para maiores esclarecimentos sobre as seqüências e os tipos de discurso ver Bronckart (1999).
} 
Já as capacidades lingüístico-discursivas estão relacionadas ao domínio das operações mais diretamente implicadas na produção textual, isto é, ao uso efetivo das unidades lingüísticas, envolvendo:

- Operações de textualização, que explicitam as relações entre os diferentes segmentos textuais (conexão e coesão nominal e verbal);

- operações de estabelecimento das responsabilidades enunciativas, envolvendo as de gerenciamento das vozes e as de expressões do posicionamento do agente nos enunciados;

- operações de construção de enunciados e de seleção de itens lexicais.

É importante esclarecer que as operações estão em interação constante, sendo que sua classificação em três tipos só é possível do ponto de vista teórico/didático (MACHADO, no prelo b).

\section{$2.3 \mathrm{O}$ modelo de análise}

Bronckart (2003) propôs, de forma correspondente aos três tipos de capacidades de linguagem, um modelo de análise que envolve a definição da situação de ação de linguagem que influencia os aspectos textuais e análise do texto produzido.

$\mathrm{Na}$ primeira fase, levantamos hipóteses sobre as representações que o produtor possivelmente detém sobre o contexto físico, o contexto sócio-subjetivo e os conteúdos a serem mobilizados para a produção. Pode-se relacionar essa fase da análise às capacidades de ação.

Para a segunda fase, que consiste na análise do texto propriamente dito, são propostos três níveis de análise, da chamada "arquitetura textual". Em relação ao primeiro nível, analisamos a infraestrutura textual, constituída pelo plano global do texto, os tipos de discursos e sua articulação que está relacionado às capacidades discursivas. No segundo nível, analisamos os mecanismos de textualização (conexão, coesão nominal e coesão verbal) e no terceiro nível analisamos os mecanismos enunciativos, ou seja, os mecanismos de inserção das diferentes vozes e as modalizações. Esses dois níveis - 
mecanismos de textualização e os mecanismos enunciativos - podem ser associados às capacidades lingüístico-discursivas.

\section{Procedimentos Metodológicos}

As resenhas analisadas foram selecionadas da revista D.E.L.T.A, que é considerada um dos mais antigos e prestigiosos periódicos brasileiros da área de lingüística.

O corpus consiste em um total de 20 resenhas selecionadas da DELTA. Selecionamos o período de 1998 a 2002 e, compreendendo esse período, fizemos uma seleção, aleatória, de 20 resenhas.

Primeiramente, fizemos um levantamento dos verbos introdutores de DR em todas as resenhas. Em seguida, a partir das capacidades de linguagem (DOLZ; SCHNEUWLY, 1998) e com base no modelo de análise de Bronckart (2003) apresentados anteriormente, fizemos uma análise dos verbos de acordo com a operação de linguagem a que se refere o verbo. Para a análise, utilizamos também outros autores que nos possibilitaram compreender o sentido de cada verbo como Vanderveken (1985); Borba (1990), Charaudeau (1992).

\section{Resultados das Análises}

Nesta seção, apresentaremos os resultados das análises. tecendo comentários, primeiramente, a respeito da ocorrência geral dos verbos introdutores de discurso relatado em nosso corpus. Em seguida, proporemos a classificação para esses verbos, com base nas operações de linguagem - de ação, discursivas e lingüístico-discursivas.

\subsection{A ocorrência dos verbos de dizer no corpus analisado}

Nossa análise permitiu observar que há uma quantidade e uma variedade muito grande de verbos usados para inserir o DR (DD e DI), totalizando 246 ocorrências de 87 verbos diferentes. Notamos, ainda, a diferença muito grande entre o número de ocorrências de verbos usados para inserir o DD (apenas 8) em relação ao número de ocorrências para inserir o DI (238). 
Verificamos também que há verbos que ocorrem muito mais freqüentemente do que outros. Como exemplo, podemos citar os verbos propor (17 ocorrências), mostrar (16 ocorrências), apresentar (15 ocorrências) e discutir (13 ocorrências), e muitos verbos como, por exemplo, descrever (1 ocorrência), declarar (2 ocorrências) e criticar (3 ocorrências) que apresentaram baixa ocorrência. Vejamos, a seguir, os verbos encontramos em nosso corpus e a sua ocorrência.

Quadro 1 - Lista dos verbos introdutores de DI com mais de 3 ocorrências

\begin{tabular}{|l|c|l|c|}
\hline $\begin{array}{c}\text { Discurso } \\
\text { indireto }\end{array}$ & Ocorrência & $\begin{array}{c}\text { Discurso } \\
\text { Indireto }\end{array}$ & Ocorrência \\
\hline Propor & 17 & Considerar & 5 \\
\hline Mostrar & 16 & Chamar a atenção & 5 \\
\hline Apresentar & 15 & Afirmar & 5 \\
\hline Discutir & 13 & Advogar & 4 \\
\hline Argumentar & 8 & Apontar & 4 \\
\hline Concluir & 8 & Destacar & 4 \\
\hline Observar & 8 & Criticar & 4 \\
\hline Demonstrar & 7 & $\begin{array}{l}\text { Tecer } \\
\text { considerações }\end{array}$ & 4 \\
\hline Abordar & 7 & Estabelecer & 4 \\
\hline Sugerir & 6 & & \\
\hline
\end{tabular}

Quadro 2 - Verbos introdutores de DI com 3 e 2 ocorrências

\begin{tabular}{|l|l|}
\hline \multicolumn{1}{|c|}{ Discurso indireto } & Discurso indireto \\
\hline Acrescentar & Focalizar \\
\hline Admitir & Indicar \\
\hline Analisar & Introduzir \\
\hline Assinalar & Lançar a hipótese \\
\hline Assumir & Postular \\
\hline Declarar & Relatar \\
\hline Defender a tese/possibilidade & Retomar \\
\hline Definir & Salientar \\
\hline Enfatizar & Tratar \\
\hline Expor & \\
\hline
\end{tabular}


Quadro 3 - Verbos introdutores de DI com apenas 1 ocorrência

\begin{tabular}{|l|l|}
\hline \multicolumn{1}{|c|}{ Discurso indireto } & \multicolumn{1}{c|}{ Discurso indireto } \\
\hline Alertar & Fazer referência \\
\hline Ampliar & Fazer revisão crítica \\
\hline Aprofundar & Justificar \\
\hline Assegurar & Realçar \\
\hline Avançar na questão & Resumir \\
\hline $\begin{array}{l}\text { Buscar comprovar a } \\
\text { hipótese }\end{array}$ & Revisitar \\
\hline Centrar & Reiterar \\
\hline Comentar & Relacionar \\
\hline Condenar & Rever \\
\hline Confessar & Levantar uma série de questões \\
\hline Confronta & Mencionar \\
\hline Convidar & Negar \\
\hline Crer & Notar \\
\hline Denominar & Traçar a história \\
\hline Descrever (Procura) & Parte de uma exposição \\
\hline Discorrer & Perguntar \\
\hline Distinguir & Fornecer argumentos \\
\hline Elucidar & Privilegiar \\
\hline Esclarecer & Reconhecer \\
\hline Examinar & Trazer a imagem \\
\hline $\begin{array}{l}\text { Fazer questão de nos } \\
\text { lembrar }\end{array}$ & Sintetizar \\
\hline Fazer sumário & Sustentar \\
\hline Falar & \\
\hline & \\
\hline
\end{tabular}

Quadro 4 - Lista de verbos introdutores de DD

\begin{tabular}{|l|c|}
\hline \multicolumn{1}{|c|}{ Discurso direto } & Ocorrência \\
\hline Dizer & 2 \\
\hline Concluir & 2 \\
\hline Assinalar & 1 \\
\hline Afirmar & 1 \\
\hline Pretender & 1 \\
\hline Terminar seu artigo & 1 \\
\hline
\end{tabular}


Para este artigo, selecionamos alguns desses verbos para serem classificados de acordo com nossos pressupostos.

\subsection{Classificação dos verbos referentes a operações de linguagem atribuída ao autor resenhado}

Os verbos foram classificados com base nas operações propostas por Bronckart, Pasquier e Dolz (1993) e por Dolz \& Schneuwly (1998). É importante esclarecer o leitor de que os verbos classificados referem-se às operações que o resenhador considera como tendo sido realizadas pelo autor resenhado no decorrer do processo de produção do texto resenhado.

\subsubsection{Verbos referentes a operações de ação}

Em relação às operações de ação, encontramos alguns verbos referentes ao objetivo ou efeito que o autor resenhado visa a produzir no destinatário. Podemos citar, como exemplo, os verbos convidar e (nos) lembrar, como se pode ver nos seguintes enunciados:

"Através dessas perguntas, o autor convida o leitor a compartilhar com ele a tarefa de levar adiante as questões discutidas [...]" (RAJAGOPALAN, 2001).

De acordo com nossa análise, os verbos que classificamos como referentes a operações de ação indicam o efeito que o autor resenhado estaria buscando produzir no destinatário, efeito este que não é dado diretamente por seu texto, mas que resulta de uma interpretação do resenhador. Ou seja, o resenhador interpreta que o autor resenhado desenvolve uma operação que visa a produzir algum efeito no destinatário.

Dos verbos encontrados em relação a esse tipo de operação, decidimos, para uma melhor explicação dessa proposta de classificação, deter-nos em uma discussão mais qualitativa de alguns desses verbos. O primeiro deles é o verbo propor, dado que foi esse verbo que apresentou o maior número de ocorrências (17), que pode ser exemplificado no enunciado a seguir. 


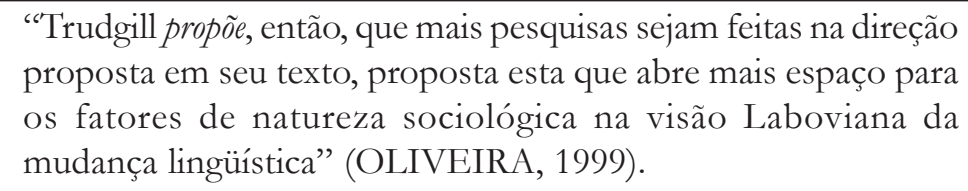

"Trudgill propõe, então, que mais pesquisas sejam feitas na direção proposta em seu texto, proposta esta que abre mais espaço para os fatores de natureza sociológica na visão Laboviana da mudança lingüística" (OLIVEIRA, 1999).

De acordo com o dicionário de Borba (1990), o verbo propor, nesse enunciado analisado, significa sugerir, apresentar, submeter à consideração, fažer a proposta de. Para Charaudeau (1992), uma proposição indica que o destinatário está na posição de receber uma oferta de que ele é beneficiário, podendo aceitá-la ou recusá-la. Assim, mesmo não havendo referência direta ao destinatário, a partir do sentido do verbo, a presença desse destinatário nas representações do produtor é facilmente inferível, ficando clara a relação que se estabelece entre enunciador e destinatário.

De acordo com esse enunciado, o autor resenhado estaria propondo que mais pesquisas sejam feitas, ficando evidente a posição social de pesquisador do enunciador/autor da obra resenhada, que supõe um leitor também pesquisador, para o qual se dirige a proposta. $\mathrm{Na}$ verdade, é o resenhador que interpreta que esse autor dirige uma proposta ao destinatário.

Outro desses verbos, que são referentes a operações de ação, com número de ocorrências significativo, é o verbo sugerir, conforme se pode observar no seguinte enunciado:

"Deborah Tannen e Cynthia Wallat propõem uma diferenciação dos tipos de estrutura de expectativa: enquadre e esquema. As autoras sugerem que se use o conceito de enquadre para denominar as informações que são co-construídas numa interação [...]" (OSTERMANN, 1999).

De acordo com Charaudeau (1992), “uma sugestão está relacionada a uma ação a realizar; portanto, o locutor supõe que o interlocutor esteja numa posição desfavorável; o interlocutor é beneficiário de uma proposta para melhorar a sua situação, sendo livre para aceitá-la ou não".

Encontramos, ainda, entre os verbos referentes a operações de ação, o verbo apresentar, que também teve um grande número de ocorrências (15), como, por exemplo, em: 
"Erickson e Schultz também apresentam uma proposta metodológica, passo a passo, de como se investigar a organização social da interação a partir de dados audiovisuais" (OSTERMANN, 1999).

Nesse enunciado, o sentido desse verbo é submeter à apreciação, ao juíro, ao exame (Borba, 1990). Percebemos que a resenhadora interpreta o efeito que o autor resenhado quer produzir no destinatário, que é levar este a apreciar, julgar uma proposta metodológica, aceitandoa ou refutando-a.

Ainda em relação às operações de ação, observamos que o resenhador também utiliza verbos que se referem às intenções do autor resenhado como os verbos procurar e buscar, nos seguintes enunciados:

"Após discorrer sobre a relatividade das listas de itens e sobre a distinção entre polissemia e homonímia, o autor procura demonstrar como podem ser descritas as entradas lexicais do português" (GONÇALVES, 2000).

"A autora busca comprovar a hipótese de que a perda do subjuntivo no francês falado nessas comunidades é decorrente de um processo de convergência entre a língua minoritária, o francês, e a língua majoritária, o inglês, ou seja, um caso de mudança induzida por contato lingüístico" (PAIVA, 1999).

Os sentidos desses verbos são bastante semelhantes: buscar indica tentativa e procurar significa empregar todos os recursos para, esforçar-se, empenhar-se. Assim, o resenhador interpreta que o autor resenhado tem intenção de demonstrar, de comprovar a hipótese e de apresentar um guia. $\mathrm{Ou}$ seja, o resenhador, ao utilizar esses verbos, atribui ao autor resenhado intenções para a atividade realizada pelo autor resenhado.

A seguir, apresentamos de modo sintético os verbos classificados como referentes às capacidades de ação: 
Verbos referentes a capacidade de ação

\begin{tabular}{|l|l|}
\hline apresentar & procurar \\
\hline buscar & propor \\
\hline convidar & submeter à consideração \\
\hline fazer a proposta de & sugerir \\
\hline lembrar & \\
\hline
\end{tabular}

\subsubsection{Verbos referentes a operações discursivas}

Nossa análise nos revelou que as operações discursivas inferidas pelo resenhador são de diferentes tipos. Em primeiro lugar, observamos que há verbos que se referem ao estabelecimento de um plano global pelo autor resenhado, indicando as partes maiores constitutivas do texto, cujos exemplos mais típicos são os verbos comecar e terminar, como exemplificamos nos seguintes enunciados:

"O capítulo 2 estuda o problema do foco do ponto de vista da prosódia. A autora começa afirmando que as línguas recorrem a diferentes meios para a identificação do foco [...]" (KATO, 2000).

"É no contexto dessa discussão que a pergunta final com a qual Celani termina seu artigo '[...] há lugar para reinos no domínio do saber?’ adquire suma importância” (RAJAGOPALAN, 1999).

Outro tipo de operação discursiva atribuída ao autor resenhado, como as operações de organização seqüencial, é explicitada por outros verbos. Como exemplos, observamos que há verbos que indicam a organização em seqüência argumentativa, como os verbos argumentar, defender a tese, justificar nos seguintes enunciados:

"Langacker argumenta que o verbo ouvir é polissêmico, com sentidos diferentes [...]" (MOURA, 2000).

"Defendendo a posição de que a Morfologia deve ser vista como componente autônomo da Gramática, independente da Sintaxe ou da Fonologia, o autor justifica a orientação gerativista assumida no livro" (GONÇALVES, 2000).

"A autora defende a tese de que o texto narrativo não se restringe à transformação da experiência" (PAIVA, 1999). 
O resenhador, ao usar os verbos argumentar e defender a tese, interpreta que o autor resenhado organizou os conteúdos do texto em forma de seqüências argumentativas. Tanto o verbo argumentar quanto o verbo justificar indica que o resenhador interpreta que o autor resenhado considera que o objeto do discurso pode ser contestado e, por isso, argumenta e justifica, Assim, esses verbos indicam que o texto traz uma seqüência argumentativa, que tem a função de convencer o destinatário da validade de posicionamento do autor diante de um objeto de discurso visto como contestável. Portanto, o resenhador, ao usar esses verbos, interpreta que operações referentes à organização argumentativa são desenvolvidas pelo autor resenhado.

Já, outros verbos indicam que o autor resenhado desenvolveu a operação de organização em forma de seqüência explicativa, como é o caso do verbo esclarecer, como podemos ver no seguinte enunciado:

"No capítulo 5, Kleiber aprofunda seu debate com Nunberg e esclarece sua alternativa teórica, baseada na noção de metonímia integrada" (MOURA, 2000).

Ao utilizar o verbo esclarecer, o resenhador interpreta a organização seqüencial, considerando que o objeto de discurso é visto pelo autor resenhado como de difícil compreensão, o que o leva a explicar.

Outros verbos mostram que o resenhador interpreta que o autor resenhado desenvolveu a operação de organização seqüencial, construindo seqüência descritiva de ações ${ }^{6}$, utilizando verbos como descrever como se pode ver nos seguintes enunciados:

"O autor procura descrever as circunstâncias em que os reparos aparecem [...]" (Paiva, 1999).

Ao utilizar o verbo descrever o resenhador indica que o autor resenhado faz o destinatário ver em detalhe os elementos de um objeto de discurso ou as diferentes ações desenvolvidas no decorrer

${ }^{6}$ Script para Bronckart (ver MACHADO, 1998). 
do tempo. Assim, o resenhador interpreta as operações do autor resenhado de "guiar o olhar" do destinatário pelas diferentes partes do texto.

Observamos, também, que há diferentes verbos que se referem a segmentos expositivos, como os verbos definir, lançar a hipótese, analisar e denominar que se referem a uma forma de organização não convencional, de esquematização. Podemos exemplificar esses verbos nos seguintes enunciados:

[...] o autor propõe que a Morfologia Flexional constitui parte do componente morfológico que atua na interface com a Sintaxe e, por isso, define flexão "como sendo um Mecanismo Lingüístico (MLF), em que a Morfologia e a Sintaxe interagem" (GONÇALVES, 2000).

"Clark lança a hipótese de denominador comum, pela qual a interação consiste em duas pistas paralelas de ações onde as pessoas tentam nivelar suas ações conjuntas para estabelecerem um denominador comum, que sirva para os propósitos do momento" (COSTA, 2001).

“Ao longo das 432 páginas, Clark não só analisa e denomina os fatos relativos ao uso da linguagem numa perspectiva teórica inovadora como, sobretudo, propõe uma teoria sobre a natureza da linguagem" (COSTA, 2001).

Por exemplo, ao usar o verbo analisar o resenhador interpreta que o autor resenhado desenvolveu operações de decompor um todo em seus elementos constitutivos (BORBA, 1990). Assim, o resenhador interpreta que o autor resenhado organiza partes de seu texto em forma de análise.

Em relação a esses enunciados citados anteriormente, observamos que o resenhador interpreta que o autor resenhado desenvolveu as operações de definir um objeto de discurso, lançar uma hipótese, nomear um objeto de discurso e analisar.

Finalmente, há verbos que indicam que o autor resenhado mobiliza um determinado conteúdo, de forma geral, sem fazer menção à forma de organização, como abordar, discutir e focalizar. 
"No capítulo 5, Santos aborda especificamente o caso de alunos falantes de espanhol, e no capítulo 6, Montenegro discorre sobre estudantes norte-americanos" (FURTOSO; GIMENEZ, 2000).

"Lobato discute advérbios e sintagmas preposicionais, dentro do quadro teórico da gramática gerativa enquanto Leitão focaliza, sob uma perspectiva funcional-cognitiva, o processo de mudança em direção a uma especialização de formas [...]" (DUARTE, 1999).

Em síntese, podemos dizer que, em relação à utilização dos verbos referentes às operações discursivas, o resenhador, na verdade, está interpretando possíveis operações do autor resenhado referentes à mobilização de conteúdos, ao modo de abordá-los e organizá-los, já que o que se descreve são operações do autor resenhado que não são, quase que como regra geral, diretamente explicitadas no texto. Desse modo, essa descrição resulta da interpretação das operações desenvolvidas pelo autor resenhado, materializadas em formas textuais. nessa subseção:

Apresentamos no quadro a seguir os verbos discutidos

Verbos referentes a operações discursivas

\begin{tabular}{|l|l|}
\hline abordar & descrever \\
\hline analisar & discutir \\
\hline argumentar & esclarecer \\
\hline começar & focalizar \\
\hline defender a tese & justificar \\
\hline definir & lançar a hipótese \\
\hline denominar & terminar \\
\hline
\end{tabular}

\subsubsection{Verbos referentes a operações lingüístico-discursivas}

Em relação à menção a operações lingüístico-discursivas, observamos que há verbos que se referem ao estabelecimento de coerência temática e de coerência pragmática. No que diz respeito ao estabelecimento de coerência temática, encontramos verbos referentes a relações existentes entre os diferentes níveis de organização de um 
texto, como os verbos chamar a atenção, enfatizar, verbos esses usados pelo resenhador para interpretar que o autor resenhado desenvolve operações com o propósito de marcar a relevância maior de um ou de outro aspecto do tema abordado. Como exemplos, temos:

"Conforme o autor chama a atenção, as pistas de contextualização são internalizadas pelos falantes e são ativadas durante a interação social [...] O autor também enfatiza o fato das convenções de contextualização permanecerem muitas vezes não-verbalizadas durante o aprendizado de uma língua estrangeira" (OSTERMANN, 1999).

Além disso, encontramos verbos que indicam que o autor resenhado articula os conteúdos dos enunciados, marcando a progressão temática, como é o caso dos verbos avançar na questão e aprofundar, nos exemplos a seguir.

"No capítulo 3, Clark avança na questão do que sejam ações conjuntas propriamente e como elas funcionam no uso da linguagem" (COSTA, 2001).

"No capítulo 5, Kleiber aprofunda seu debate com Nunberg e esclarece sua alternativa teórica, baseada na noção de metonímia integrada" (MOURA, 2000).

Já em relação ao estabelecimento de coerência pragmática, encontramos diferentes verbos que se referem às operações de inserção de vozes, como é o caso do verbo retomar e de fazer referência no enunciado a seguir, em que o resenhador interpreta que o autor resenhado estabeleceu relações intertextuais com outros autores/textos:

"O autor $f a$ r, ainda, referência a vários nomes e trabalhos voltados para crioulística em diferentes regiões. Aliás, essa é uma seção constituída por citações e referências, num verdadeiro desafio a qualquer vivente" (OLIVEIRA, 1998).

"Trabalhando dentro do quadro desenvolvido por Weinreich, Labov \& Herzog (1968), Ferguson retoma duas questões lá colocadas : (1) por que acontece [...], (2) como é uma dada [....]" (OLIVEIRA, 1999). 
O resenhador, ao usar o verbo retomar, indica que o autor resenhado traz em cena outros autores para retomar duas questões colocadas por eles, o que evidencia a relação estabelecida com outras vozes.

Outros verbos, como condenar e criticar, indicam a interpretação do resenhador sobre o posicionamento do autor em relação às vozes inseridas, como podemos ver nos seguintes enunciados:

"Sob o título de "Cassandra, Fênix e outros mitos", Marcos Bagno não poupa ironia em condenara arrogância com que alguns se acham no direito de opinar a respeito de como os outros devem se comportar em matéria de linguagem" (RAJAGOPALAN, 2002).

"Ao criticar os cientistas cognitivos por tenderem a estudar os falantes e os ouvintes, como indivíduos e os cientistas sociais, por outro lado, por tenderem a estudar o uso da linguagem como uma atividade exclusivamente conjunta, ou seja, rejeitando os pensamentos e ações dos indivíduos, Clark abre espaço para lançar a sua teoria" (COSTA, 2001).

Ainda em relação às operações lingüístico-discursivas, encontramos verbos que se referem à possível operação de estabelecimento de posicionamento (em relação à verdade do enunciado) desenvolvida pelo autor resenhado, como os verbos postular, assumir e advogar tal como podemos ver nos exemplos abaixo.

"Interpretando tais fatos, $\mathrm{Z}$ postula que eles decorrem do fato de que o caso nominativo no italiano, ao contrário do espanhol, precisa ser abertamente checado em Spec de T, com exceção das construções locativas" (KATO, 2000).

"Z assume com Kayne (1994) que todas as línguas projetam seus complementos à direita [...]" (KATO, 2000)

“ [...] o autor adota como pano de fundo a visão pós-moderna da ciência e da distribuição de conhecimentos e advoga uma postura abertamente crítica" (RAJAGOPALAN, 1999). 
Como vemos, a maioria dos verbos diz respeito a uma interpretação segundo a qual o autor resenhado considera como verdadeiros os enunciados que a eles se seguem. Assim, por exemplo, o verbo advogar significa defender, sustentar, sendo que, para Vanderveken (1985), sustentar uma proposição é afirmar publicamente e com força. Já o verbo postular significa defender como verdadeiro. O verbo assumir significa tomar para si e ainda estabelece, no enunciado acima, a relação com outras vozes.

Já o verbo dizer tem um valor de posicionamento mais neutro em relação à verdade do enunciado, como se pode ver no seguinte enunciado:

"Mas a relação entre a pintura e o livro de Mey se revela ainda mais emaranhada. Para complicar as coisas ainda mais, diz Mey, as primeiras tiragens do livro apresentaram um outro fator complicado"(RAJAGAPOLAN, 2001).

A seguir, fizemos uma síntese dos verbos classificados como referentes a operações lingüístico-discursivas.

Verbos referentes a operações lingüístico-discursivas

\begin{tabular}{|l|l|}
\hline advogar & criticar \\
\hline aprofundar & dizer \\
\hline assumir & enfatizar \\
\hline avançar na questão & fazer referência \\
\hline condenar & postular \\
\hline chamar a atenção & retomar \\
\hline
\end{tabular}

Em suma, podemos constatar que o resenhador utiliza verbos que se referem:

1) às operações de ação, verbos estes usados pelo resenhador quando ele interpreta o objetivo ou $\mathrm{O}$ efeito que o autor resenhado quer atingir;

2) às operações discursivas, verbos estes usados pelo resenhador quando ele interpreta o modo de organização e de escolha do conteúdo temático desenvolvidos pelo autor resenhado; 
3) às operações lingüístico-discursivas, verbos estes usados pelo resenhador quando ele interpreta a relevância temática, a articulação dos segmentos do texto, o estabelecimento de relações com outras vozes.

\section{Comentários dos Resultados}

A partir do sentido dos verbos, propomos uma classificação para os mesmos, porém é necessário esclarecer que não se trata de uma classificação rígida, estanque, pois sabemos que as operações estão em interação constante, sendo classificadas em três tipos apenas do ponto de vista teórico e didático. Dessa forma, muitos verbos que classificamos como indicando uma das operações de linguagem, na verdade, podem indicar mais de uma das operações ao mesmo tempo.

Para explicar essa interação, podemos retomar os exemplos dos enunciados nos quais há os verbos esclarecer e argumentar, referentes às seqüências explicativa e argumentativa, respectivamente.

"No capítulo 5, Kleiber aprofunda seu debate com Nunberg e esclarece sua alternativa teórica, baseada na noção de metonímia integrada" (MOURA, 2000).

"Langacker argumenta que o verbo ouvir é polissêmico, com sentidos diferentes [...]" (MOURA, 2000).

O resenhador, ao usar o verbo esclarecer, interpreta que o autor resenhado tem o objetivo de fazer o destinatário compreender um objeto de discurso visto como de difícil compreensão pelo destinatário, e ao usar o verbo argumentar o resenhador interpreta que o autor resenhado tem o objetivo de convencer o destinatário da validade de seu posicionamento diante de um objeto visto como contestável. Assim, os verbos esclarecer e argumentar indicam a organização dos conteúdos em seqüência argumentativa e explicativa, mas, ao mesmo tempo, indicam que o autor resenhado visa a atingir um determinado objetivo em relação ao destinatário. 
Portanto, enfatizamos que as operações não são estanques e, portanto, também não é estanque a sua interpretação pelo resenhador. Ao propormos a classificação, evidenciamos a interpretação da operação dominante que o resenhador atribui ao autor resenhado.

Assim, pela análise desenvolvida, considerando que se trata de resenhador especialista e, portanto, de um "bom leitor", podemos deduzir que, para desenvolver a resenha, ele mobiliza representações adequadas sobre o contexto físico e sócio-subjetivo da ação de linguagem do autor resenhado; identifica os tipos de seqüências e as outras formas de organização existentes no texto resenhado; observa as relações estabelecidas entre os diferentes níveis de organização do texto; percebe o modo de gerenciamento das vozes e o modo de o autor resenhado se posicionar diante de um enunciado.

\section{Conclusão}

Após compreender as fronteiras do discurso relatado, foi possível a identificação dos verbos. A análise dos dados marca nitidamente a resenha como um gênero metatexual, com uma quantidade e uma variedade muito grande de verbos usados para relatar o discurso do outro, totalizando 86 verbos em 20 resenhas, sendo predominante o discurso indireto (com 237 ocorrências) e quase insignificante o discurso direto (com 8 ocorrências). A predominância do uso do discurso indireto parece ser uma característica do gênero em questão e da comunidade discursiva em que esse gênero circula.

Verificamos que, em relação aos verbos referentes às operações de ação, encontramos alguns verbos como convidar, que têm como função levar o destinatário a fazer algo e, o resenhador, ao usar esses verbos, está interpretando as operações do autor resenhado em relação ao destinatário. Por sua vez, no que se refere aos verbos referentes às operações discursivas, encontramos muitos verbos referentes às operações de apresentação e de organização do conteúdo temático. Já, no que diz respeito aos verbos referentes às operações lingüístico-discursivas, o resenhador utiliza verbos que se referem tanto às operações de estabelecimento de coerência temática, interpretando que o autor resenhado desenvolveu operações referentes ao estabelecimento da relevância temática e referentes à articulação dos 
diferentes segmentos textuais, quanto às operações de estabelecimento da coerência pragmática, interpretando que o autor resenhado desenvolveu operações de relacionamento entre diferentes autores/ textos e de inserção de suas vozes e operações para o estabelecimento de seu posicionamento em relação ao grau de verdade do enunciado.

A partir dessa análise, parece-nos que podemos defender a tese de que o ensino de produção de resenhas passa necessariamente pelo ensino da interpretação das diferentes operações de linguagem. Essa tese, a nosso ver, também seria válida para o ensino da produção de outros gêneros acadêmicos metatextuais, ou que apresentam segmentos metatextuais, como os resumos, os projetos de pesquisa, os artigos, as dissertações e as teses, e também para o ensino de outros gêneros pertencentes a outras esferas de atividade, por exemplo, a jornalística, que se caracterizam pela metatextualidade. Assim, para a maestria nas operações necessárias para a produção desses textos, é necessário um trabalho aprofundado e intenso do texto comentado que esteja ligado à capacidade de interpretar as operações realizadas pelo autor comentado.

\section{Resenhas Analisadas}

COSTA, Janete Sander. Resenha de: CLARK, Herbert H. Using Language. Cambridge, UK: Cambridge University Press, 1996. D.E.L.T.A., v. 17, n. 2, p. 343-352, 2001.

DUARTE, Maria Eugênia Lamog. Resenha de: HEYE, J. (Org.) Flores Verbais: uma homenagem lingüística e literária para Eneida do Rego Monteiro Bomfim no seu $70^{\circ}$ aniversário. Rio de Janeiro: Editora 34 Associada à Editora Nova Fronteira, 1995. D.E.L.T.A., v. 14, n. 1, p. 185-188, fev. 1998.

FURTOSO, Viviane B.; GIMENEZ, Telma N. Resenha de: CUNHA, M. J.; SANTOS, P. (Orgs.) Ensino e Pesquisa em Português para Estrangeiros - Programa de Ensino e Pesquisa em Português para Falantes de Outras Línguas (PEPPFOL). Brasília: Edunb, 1999. D.E.L.T.A., v. 16, n. 2, p. 443-447, 2000. 
GONÇALVES, Carlos Alexandre V. Resenha de: ROCHA, Luiz Carlos de Assis. Estruturas Morfológicas do Português. Belo Horizonte: Ed. da UFMG, 1998. (Coleção Aprender). D.E.L.T.A., v. 16, n. 1, p. 175-181, 2000.

KATO, Mary A. Resenha de: ZUBIZARRETA, Maria Luiza. Prosody, Focus, and Word Order. Cambridge, Massachusetts/ London.The MIT Press, 1998. D.E.L.T.A., v. 16, n. 1, p. 155-174, 2000.

MOURA, Heronides Maurilio de Melo. Resenha de: KLEIBER, G. Problèmes de Sémantique - la polysémie en questions. Villeneuf d'Ascq: Presses Universitaires du Septentrion, 1999. D.E.L.T.A., v. 16, n. 2, p. 431-441, 2000.

OLIVEIRA, Dercir Pedro de. Resenha de: COUTO, H. H. do. Introdução ao Estudo das Línguas Crioulas e Pidgins. Brasília: Editora Universidade de Brasília, 1996. D.E.L.T.A., v. 14, n. 1, p. 189-194, fev. 1998.

OLIVEIRA, Marco Aantônio de. Resenha de: Towards a social science of language - papers in honor of William Labov volume 1: variation and change in language and society. D.E.L.T.A., v. 15, n. 2, p. 373410, 1999.

OLIVEIRA, Roberta Pires de. Resenha de: ILARI, Rodolfo. Introdução à Semântica. brincando com a gramática. São Paulo: Contexto, 2001. D.E.L.T.A., v. 18, n. 2, p. 345-353, 2002.

OSTERMANN, A. C.. Resenha de: RIBEIRO, B. T.; GARCEZ, P. M. (Orgs.) Sociolingüística Interacional: antropologia, lingüística e sociologia em análise do discurso. Porto Alegre: AGE, 1998. D.E.L.T.A., v. 15, n. 2, p. 367-371, 1999.

PAIVA, Maria da Conceição de. Resenha de: GUY, G.; FEAGIN, C.; SCHIFFRIN, D.; BAUGH, J. (Eds.) Towards a social science of language. V.2: Social interaction and discourse structures. Amsterdan/ Philadelphia: John Benjamins Publishing Company, 1997. Current issues in linguistic theory, 128. D.E.L.T.A., v. 15, n. 1, fev 1999. 
RAJAGOPALAN, Kanavillil. Resenha de: MEY, Jabob L. Pragmatics: An Introduction. 2. ed. Mass., EUA / Oxford, Reino Unido: Blackwell Publishers, 2001. D.E.L.T.A., v. 17, n. 2, p. 337-342, 2001.

Resenha de: SIGNORINI, I.; CAVALCANTI, M. C. (Orgs.) Lingüística Aplicada e Transdisciplinaridade: Questões e Perspectivas. Campinas: Mercado de Letras, 1998. D.E.L.T.A., v. 15, n. 2, p. 355359, 1999.

\section{Referências Bibliográficas}

ARAÚJO, Antonia Dilamar. Lexical signalling: a study of unspecificnouns in book reviews. 1996. Tese (Doutorado em Lingüística) Universidade Federal de Santa Catarina, Florianópolis.

AUTHIER-REVUZ, Jacqueline. Palavras incertas: as nãocoincidências do dizer. Trad. Claudia R.C. Pfeiffer; Gileade P. de Godoi; Luiz F. Dias; Maria Õ. Payer; Mónica Zoppi-Fontana; Pedro de Souza; Rosângela Morello; Suzy Lagazzi-Rodrigues. Campinas: Editora da Unicamp, 2001.

Hétérogénéite montrée et hétérogénéite constitutive: éléments pour une approche de l'autres dans le discours. DRLAV, n. 26, 1982.

BAKHTIN, Mikhail. [1979] Estética da criação verbal. Trad. Maria Ermantina G. G. Pereira. São Paulo: Martins Fontes, 2000.

BEZERRA, Benedito Gomes. A distribuição das informações em resenhas acadêmicas. 2001. Dissertação (Mestrado em Lingüística) - Universidade Federal do Ceará, Fortaleza.

BORBA, Francisco da Silva (Coord.). Dicionário gramatical de verbos do português contemporâneo do Brasil. São Paulo : Editora Unesp, 1990.

BRONCKART, Jean-Paul. [1997] Atividades de linguagem, textos e discursos: por um interacionismo sócio-discursivo. 2. ed. Trad. Anna Rachel Machado. São Paulo: EDUC, 2003. 
CHARAUDEAU, Patrick. Grammaire du sens et de l' expression. Paris: Hachette Éducation, 1992.

DOLZ, Joaquim; SCHNEUWLY, Bernard. Pour un enseignement de 1'oral - initiation aux genres formels à l'école. Paris: ESF, 1998. (Collection Didactique du Français).

.; PASQUIER, Auguste; BRONCKART, Jean-Paul. L'acquisition des discours: emergence d'une competence ou apprentissagem de capacities langagières diverses? Etude de Linguistique Appliquée, n. 89, p. 25-35, 1993.

GENETTE, Gerard. Palimpsestes. Paris: Le Seuil, 1981.

MACHADO, Anna Rachel. A formação de professores como locus de construção de conhecimentos científicos. Revista da Anpoll, 2004.

. Seminário de Práticas de Análises: os textos dos alunos como índice para avaliação das capacidades de linguagem. In: COLÓQUIO FRANCO-BRASILEIRO DE ANÁLISE DE DISCURSO, 3. Anais... Belo Horizonte, no prelo(a).

. A perspectiva interacionista sócio-discuriva de Bronckart. In: MEURER, J.L.; BONINI, A.; MOTTA-ROTH, D. (Orgs.). Gêneros sob perspectivas diversas. no prelo(b).

MAINGUENEAU, Dominique. [1998] Análise de textos em comunicação. Trad. Cecília P. de Souza-e-Silva; Décio Rocha. São Paulo: Cortez, 2001.

[1987] Novas tendências em Análise do Discurso. 3. ed. Trad. Freda Indursky, Campinas: Pontes/ Editora da Unicamp, 1997.

MATÊNCIO, Maria de Lourdes Meirelles Atividades de (re) textualização em práticas acadêmicas: um estudo do resumo. SCRIPTA, Belo Horizonte, v. 6, n. 11, p. 109-122, 2002.

MOTTA-ROTH, Désirée. (Org.) Princípios básicos: redação acadêmica. Laboratório de Leitura e Redação, Universidade Federal de Santa Maria, 2003. 
Rhetorical features and disciplinary cultures: a genrebased study of academic book reviews in linguistics, chemistry and economics. 1995. Tese (Doutorado em Lingüística) - Universidade Federal de Santa Catarina, Florianópolis.

MUNIZ-OLIVEIRA, Siderlene. Os verbos de dizer em resenhas acadêmicas e a interpretação do agir verbal. 2004. Dissertação (Mestrado em Lingüística Aplicada e Estudos da Linguagem) Pontifícia Universidade Católica de São Paulo, São Paulo.

SILVA, Jane Quintiliano Guimarães; MATA, Maria Aparecida da. Proposta tipológica: um estudo exploratório das práticas de ensino da leitura e da produção de textos acadêmicos. SCRIPTA, Belo Horizonte, v. 6, n. 11, p. 123-132, 2002.

VANDERVEKEN, Daniel. Les actes de discours: essai de philosophie du langage et de l'espirit sur la signification des énonciations. Liege, Bruxelles: Pierre Mardaga Editeur, 1985. 